\title{
How to avoid the violation of ethics in research and publication? Gupta S1 $1 \mathrm{D} \otimes$, Rajak $^{2}$ iD
}

'Sujaya Gupta, Assistant Professor, Department of Periodontics and Oral Implantology, Kathmandu Medical College Teaching Hospital, Bhaktapur, Nepal; ${ }^{2}$ Ashik Rajak, Assistant Editor, Journal of Kathmandu Medical College, Kathmandu, Nepal.

T The practice of "ethics" has been something that has been talked about a lot of times. However, most of us, knowingly or unknowingly, have been culprit of conducting some form of ethical misconduct during our career. The topic itself is very vast, nonetheless, through this article, we would like to brush up the most fundamental principles of ethics in research and publication that have been heard and read by many, understood by few, and practiced rarely.

The impact of violating ethics in research and publication may not always be life and death situation like in our clinical practice. Many of us, even senior researchers and academicians often overlook the fact that, what we are writing will be read and preserved for future generations for years - to read, critically analyse, and praise or degrade/ denounce depending upon the content. Before we delve into the ways to avoid being the culprit unknowingly, we have listed a few infamous cases of violation of ethics, the consequences of whose fraudulent ways you may search and read in your free time:

Access this article online

Website: www.jkmc.com.np

DOI: https://doi.org/10.3126/jkmc.v9i1.34021

HOW TO CITE

Gupta S, Rajak A. How to avoid the violation of ethics in research and publication? J Kathmandu Med Coll. 2020;9(1):1-4.

Address for correspondence

Dr. Sujaya Gupta

Assistant Professor, Department of Periodontics and Oral Implantology

Kathmandu Medical College Teaching Hospital

Bhaktapur, Nepal

E-mail: sujayaagupta@gmail.com

Copyright @ 2020 Journal of Kathmandu Medical College (JKMC)

ISSN: 2019-1785 (Print), 2091-1793 (Online)

(i) \& This work is licensed under a Creative Commons Attribution-Non Commercial 4.0 International License.
- Abida Sophina Jamal

- Andrew Wakefield

- Anil Potti

- Cyril Burt

- Diederik Stapel

- Dipak K. Das

- Ernst Haeckel

- Havasupai tribe law suit and settlement ${ }^{1}$

- Jan Hendrk Schon

- John Darsee ${ }^{2}$

- Malcolm Pearce ${ }^{2}$

- Nuremberg trial

- Ram B. Singh ${ }^{2}$

- Ranjit K. Chandra ${ }^{2}$

- Robert A. Slutsky

- Robert Millikan

- Stefano Fiorucci

- Tuskegee syphilis study

- Ward Churchil

- William McBride

- William Summerlin²

- Willowbrook hepatitis study

- Woo-suk Hwang (South Korean stem cell researcher) ${ }^{2}$

- Yoshitaka Fujii ${ }^{3}$

- Yuhji Saitoh ${ }^{3}$

Most of these researchers were award-winning including the prestigious Noble Prize and all were considered geniuses in their respective fields, but violation of research misconduct led to their downfall and disgrace. In this highly competitive world of "publish or perish," we happen to violate research and publication ethics quite a number of times knowingly or unknowingly. Hence, in the race for promotion, let us not do something that can lead to the retraction of the publication and a lifetime of regrets $^{3-6}$. For a scientific journal, it is essential to follow the ethical principles in scientific publications to maintain the readers' trust and to uphold its reputation? ${ }^{7}$. One of the easiest ways to decrease the proportion of scientific misconduct and violation of research and publication ethics is to increase our knowledge regarding the same. 
Research misconduct can take place at any stage of research continuum, from proposal writing to publication $^{8}$. The Committee on Publication Ethics (COPE), World Medical Association (WMA), World Association of Medical Editors (WAME), International Committee of Medical Journal Editors (ICMJE), Good Clinical Practice (GCP), Retraction Watch, and the Office of Research Integrity (ORI) are few of the prominent organisations that have taken many initiatives, and formed guidelines to maintain the highest ethical conduct in research and publication ${ }^{3,8-11}$. The simplest way to avoid violating the ethical principles is to understand what they constitute and mean.

Some commonly encountered research and scientific misconducts are $2,4,7,9,11-13$ :

- $\quad$ Fabrication - Making up data or results. Nepalese researchers humorously refer to this as "Chautari data collection," where the data collectors / enumerators sit under a big banyan / peepal tree - the chautari, and just fill the proforma without collecting any information.

- Falsification - Manipulating research materials / equipment / processes or changing / omitting data or results to get expected sample size or result.

- Plagiarism - Pronounced as "play-ji-a-rizm" (not "play-gi-a-rizm"), is the misappropriation of ideas / processes / someone else's words without appropriate citation or credit.

- Self - plagiarism (Text recycling) - When sections of the same text are included in more than one publication of the same author. Opinions are however divided, as to how much text overlap with an author's own previous publications is acceptable.

- Salami publication - Publication of two or more articles from a single research. This however can be acceptable under certain circumstances.

- Imalas publication - It is "salami" spelled backwards. When one publishes another article after extending the study duration or the period of investigation. Here, the samples or data from previous publication are also included in the new submission.

- Authorship disputes - Mainly in the order of authors and type of authorship such as honorary / guest / gifted and ghost authorship. Other issues with authorship are: adding new author at galley proof stage; forging the signature of co-authors; and lengthy authors list by including spouse's name or names of everyone in the department. These can be minimised by following the ICMJE criteria mentioned below ${ }^{11}$.

- Duplicate or redundant submission/publication

- Any research can be submitted to only one journal at one particular instance and will need to be withdrawn - the request has to be accepted by the journal before it can be submitted to another journal; publishing the same article in more than one journal, and sometimes, publishing the same paper changing the authors.

Other common ethical violations include:

- $\quad$ Failure to comply with the mandates of regulatory bodies - In context to Nepal it means, not complying with the rules and regulations of the Ethical Review Board of Nepal Health Research Council (ERB, NHRC), the Institutional Review Board/Committee (IRB/IRC), rules and regulations of other authorities like the Nepal Medical Council (NMC) and other applicable acts of the Government of Nepal.

- Indulging in activities that require appropriate rights, permissions, and copyrights without their acquisition.

- Lacking or faking ethical approval.

- Incorporating / including figures from the internet without mentioning the source.

- Manipulating or editing images and right-left reversal.

- $\quad$ Submitting a paper for publication without consent or knowledge of co-authors.

- $\quad$ Not stating "conflict of interest".

- Not respecting privacy and confidentiality of study participants.

- Reviewers rejecting proposal or manuscript and later submitting their own work along similar line.

- Usage of abusive or rude language by reviewers.

- Causing delay in publication or ethical approval due to conflict of interest.

- Fear of being critical to senior author further affecting the review process.

- Intention to cheat with blatant disregard to ethical principles.

- Not paraphrasing when citing and copying entire sentences or paragraphs.

- Authors not being concerned about the quality of their work and rather wanting immediate publication.

A survey done by Looi et al. ${ }^{12}$ among editors, editorial board, and editorial staff of 54 journals of Asia Pacific Association of Medical Journal Editors (APAME) 
reported encountering these author misconducts more commonly: plagiarism, duplicate publication, unjustified authorship, authorship disputes, data falsification, data/ image manipulation, conflict of interest, copyright violation, and confidentiality breach. Plagiarism ranked the topmost $(75 \%)$ while confidentiality breach was the least common (9.6\%).

In a country like ours, where research culture is still in its budding stage, we mostly talk about ethical violation at the researcher's or author's end whereas reviewer misconduct is often overlooked. Looi et al. ${ }^{12}$ reported the most commonly encountered misconduct from the reviewer's side to be conflict of interest, plagiarism, obstructive behaviour, abusive language and breach of confidentiality. Conflict of interest ranked highest (18.8\%), abusive language (12.5\%) and breach of confidentiality (12.5\%) were the least problematic ethical concern among reviewers.

The ICMJE recommends that authorship be based on the following four criteria ${ }^{11}$ :

i. Substantial contributions to the conception or design of the work; or the acquisition, analysis, or interpretation of data for the work; AND

ii. Drafting the work or revising it critically for important intellectual content; AND

iii. Final approval of the version to be published; AND

iv. Agreement to be accountable for all aspects of the work in ensuring that questions related to the accuracy or integrity of any part of the work are appropriately investigated and resolved.

The ethics in research and publication is heavily dependent on authors' ethical conduct, efficiency of peer reviewers, editorial judgement, and the detection of its violation is not easy ${ }^{12}$. When you are an editor in a health journal, despite the lack of the badge you become a moral police for scientific publication. Having received this opportunity early in our careers as academicians and over the years, we along with the editorial team we have been working with then and now, have helped and guided numerous researchers to publish ethically. To avoid disputes and retractions after publication and to minimise violations of research and publication ethics thereby strengthening the ethical culture among researchers, authors and reviewers, here are few pointers that would be of help to everyone:

- Ethical practice should begin early in research. In fact, it is important for all authors to be clear about their role in the research process and should take responsibility for their individual part. The ERB/IRC/
IRB can be of great help and technical support at this stage. To avoid authorship disputes later, the authorship order has to be decided following the ICMJE criteria. ${ }^{11}$

- It is essential to obtain ethical clearance from the IRB and other committees. Previously for those who did not have access to ethical committees, just following the principles outlined in the latest revised version of Declaration of Helsinki (by WMA) ${ }^{10}$ was allowed. However, in our context if there are no IRBs/IRCs in the institute, getting approval from NHRC is advised.

- Studies involving people, animals, medical records, and human tissues should be conducted ethically ${ }^{7,10}$.

- If the methodology is modified after receiving ethical approval, the respective ethical committee (ERB/IRB/IRC) needs to be informed and the updated proposal or amendment has to be submitted.

- Individual journal's guidelines have to be strictly followed and various ethical aspects specific to that journal have to be read thoroughly.

- $\quad$ Respective guidelines for various types of studies have to be followed, e.g., for clinical cases, CAse REport (CARE) guidelines, Animal Research: Reporting of In Vivo Experiments (ARRIVE) for animal studies and so on. The EQUATOR network provides detailed information regarding the same ${ }^{14}$.

- Using anti-plagiarism software - There are many software available for checking plagiarism, however, it is not always affordable by individuals or a journal. Thus, we can take benefit of some free plagiarism checking sites, which often verify 1000 words at a time. It can be tedious and not as accurate as the paid versions, but it is better than not checking and further decreases the chance of getting your article rejected by a journal due to plagiarism issue.

- Seeking technical support on adaption of image for publication purpose without undue manipulation.

- $\quad$ Refraining from doing proxy signatures of coauthors.

- For optimum privacy and confidentiality, using patients' names, initials, hospital numbers, or any other disclosing information unless the information is scientifically essential should be avoided?

- Receiving "informed consent" and "assent" as required, before starting any study.

- Obtaining the rights and permissions whenever required and mentioning clearly in writing the copyright transfer and permissions.

- Citing any article only after having read the full article and having access to it from a verifiable source rather than citing it based on its abstract. 
- Avoiding citing articles written in languages other than English or one's own native language, unless one has used language converter or interpreter or can understand the language.

- Attending workshops and trainings to update current knowledge.

In summary, abiding by ethical practices is important not only to protect our own reputation but for the continuity

1. Garrison NA. Genomic justice for native Americans: impact of the Havasupai case on genetic research. Sci Technol Human Values. 2013;38(2):201-23. [PubMed | Full Text | DOI]

2. Smith R. Research misconduct: the poisoning of the well. J R Soc Med. 2006;99(5):232-7. [PubMed | Full Text | DOI]

3. Saikia P, Thakuria B. Retraction of papers authored by Yuhji Saitoh - Beyond the Fujii phenomenon. Indian J Anaesth. 2019 Jul;63(7):571-84. [PubMed | Full Text | DOI]

4. Moylan EC, Kowalczuk MK. Why articles are retracted: a retrospective cross-sectional study of retraction notices at BioMed Central. BMJ Open. 2016 Nov;6(11):e012047. [PubMed | Full Text | DOI]

5. Ahimastos $A A$, Aggarwal A, Savarirayan $R$, Dart $A M$, Kingwell BA. A role for plasma transforming growth factor-beta and matrix metalloproteinases in aortic aneurysm surveillance in Marfan syndrome? Atherosclerosis. 2010 Mar;209(1):211-4. [PubMed | Full Text | DOI]

6. Bae S, Kim MC, Kim JY, Cha HH, Lim JS, Jung J, et al. Effectiveness of surgical and cotton masks in blocking SARS-CoV-2: A controlled comparison in 4 patients. Ann Int Med. 2020 Jul 7;173(1):W22-W3. [PubMed | Full Text | DOI]

7. Peh WCG, Ng KH. Publication ethics and scientific misconduct. Singapore Med J. 2010 Dec;51(12):90812. [PubMed | Full Text]

8. Jones R. Research misconduct. Fam Pract. 2002 Apr;19(2):123-4. [PubMed | Full Text | DOI]

9. Committee On Publication Ethics (COPE). Promoting integrity in scholarly research and its publication [internet]. Hampshire, United Kingdom: COPE; 2020. of healthy life as well. False or fake information can lead to incorrect management and planning. As true picture of any condition or disease is available through research, it is of utmost importance that ethical principles be followed by everyone in the scientific community, during research, peer review, and publication process.

"Ethics is knowing the difference between what you have a right to do and what is right to do." - Justice Potter Stewart ${ }^{15}$

\section{REFERENCES}

Available from: https://publicationethics.org/ [Full Text]

10. World Medical Association (WMA). Declaration of Helsinki - Ethical principles for medical research involving human subjects [internet]. Brazil: WMA; 2013. Available from: https://www.wma.net/policiespost/wma-declaration-of-helsinki-ethical-principlesfor-medical-research-involving-human-subjects/ [Full Text]

11. International Committee of Medical Journal Editors (ICMJE). Defining the role of authors and contributors [internet]. ICMJE; 2020. Available from: http://www. icmje.org/recommendations/browse/roles-andresponsibilities/defining-the-role-of-authors-andcontributors.html [Full Text]

12. Looi LM, Wong LX, Koh CC. Scientific misconduct encountered by APAME journals: an online survey. Malays J Pathol. 2015 Dec;37(3):213-8. [PubMed | Full Text]

13. Abdollahi M, Gasparyan AY, Saeidnia S. The urge to publish more and its consequences. Daru J Pharmaceut Sci. 2014 Jun 30;22(1):53-5. [PubMed | Full Text | DOI]

14. Enhancing the QUAlity and Transparency Of health Research (EQUATOR). Reporting guidelines for main study types [internet]. United Kingdom: EQUATOR; 2020. Available from: https://www.equator-network. org/ [Full Text]

15. Ben RM, Rogers T. Vocational rehabilitation ethics [internet]. Ontario Society of the Vocational Rehabilitation Association; 2012. Available from: https://www.thomsonrogers.com/wp-content/ uploads/2015/06/rmb-vocational-rehabilitationethics-2012.pdf [Full Text] 